\title{
A review of the role of oxidative stress in the pathogenesis of eye diseases
}

\section{OA Oduntan* and KP Mashige ${ }^{\dagger}$}

Discipline of Optometry, School of Physiotherapy, Sport Science and Optometry, University of KwaZulu-Natal, Westville Campus, Private Bag X54001, Durban 4000 South Africa

<oduntanoa@ukzn.ac.za>

$<$ mashigek@ukzn.ac.za>

Received 20 June 2011; revised version accepted 2 November 2011

\begin{abstract}
Free radicals, referred to as oxidants are molecules in the body with unpaired electrons, hence are unstable and ready to bond with other molecules with unpaired electrons. They include Reactive Oxygen Species (ROS) such as superoxide anion radicals $\left(\cdot \mathrm{O}^{-}\right)$, hydrogen peroxide $\left(\mathrm{H}_{2} \mathrm{O}_{2}\right)$, and hydroxyl free radicals $(\cdot \mathrm{OH})$. Endogenous sources of ROS include metabolic and other organic processes, while exogenous sources include ultraviolet radiation and environmental toxins such as smoke. Antioxidants (oxidant scavengers) such as ascorbate, alpha-tocopherol and glutathione as well as various enzymatic compounds such as superoxide dismutase (SOD), catalase and glutathione reductase are also present in the body and in many foods or food supplements. An imbalance between oxidants and antioxidants in favour of oxidants
\end{abstract}

is termed oxidative stress and can lead to cell or tissue damage and aging. Oxidative stress has been implicated in the pathogenesis of many serious systemic diseases such as diabetes, cancer and neurological disorders. Also, laboratory and epidemiological studies have implicated oxidative stress in the pathogenesis of the majority of common serious eye diseases such as cataract, primary open angle glaucoma and age-related macular degeneration. In this article, we reviewed the current information on the roles of oxidative stress in the pathogenesis of various eye diseases and the probable roles of antioxidants. Eye care practitioners will find this article useful as it provides information on the pathogenesis of common eye diseases. (S Afr Optom 2011 70(4) 182-190)

Key Words: Oxidants, antioxidants, reactive oxygen species, oxidative stress, eye diseases.

\section{Introduction}

Free radicals (oxidants) have been associated with various eye and systemic diseases as well as ageing processes. They are scavenged by antioxidants, therefore reducing or preventing their destructive activities in the body. An imbalance between oxidants and antioxidants in favour of oxidants (oxidative stress) causes cell death and tissue damage and may potentiate ageing process. The roles of oxidants, antioxidants and oxidative stress in the pathogenesis of eye diseases are discussed below.

\section{Free radicals (Oxidants)}

Generally, chemical bonds split in a way that does not leave a molecule with an odd unpaired electron, but when weak bonds split, free radicals are formed ${ }^{1}$. Free radicals are chemical species that have odd number of electrons, hence are very unstable and react quickly with other molecules, trying to capture the needed electron to gain stability ${ }^{1}$. When the attacked molecule losses its electron, it becomes a free radical itself, and a chain of reaction ensues which may eventually result in the disruption of a living cell ${ }^{1,2}$ One widely held hypothesis for the damaging effects 
of free radicals is the 'free radical theory' of aging, which states that the generation of free oxygen radicals inside cells accelerates aging process through random and sequential damage to cell components ${ }^{3}$.

Free radicals referred to as reactive oxygen species (ROS) encompass a variety of diverse chemical species such as superoxide anions $\left(\cdot \mathrm{O}^{-}\right)$, hydroxyl radicals $(\cdot \mathrm{OH})$ and hydrogen peroxide $\left(\mathrm{H}_{2} \mathrm{O}_{2}\right)$. A major part of ROS originates as by-products of anaerobic metabolism in the mitochondria ${ }^{2}$. These endogenous components include mitochondrial peroxisomes, lipoxygenases and NADPH oxidate. Exogenous sources of ROS include ultraviolet light, ionizing radiations, chemotherapeutics, inflammatory cytokines, environmental toxins and growth factors ${ }^{2,4-6}$. Living in an oxygenated environment has required the evolution of effective cellular strategies to detect and detoxify metabolites of $\mathrm{ROS}^{4}$. The free radical theory proposes that ageing is the cumulative result of oxidative damage to the cells and tissues of the body that arises primarily as a result of aerobic metabolism ${ }^{5}$. The theory may also be used to explain many of the structural features that develop with ageing including the lipid peroxidation of the membranes, formation of age pigments, cross linkages of proteins, DNA damage and decline of mitochondrial function ${ }^{5}$. Free radicals inflict damage to the mitochondria ${ }^{7}$ and have been implicated in the pathogenesis of serious systemic diseases such as Alzheimer's, diabetes and Parkinson's disease ${ }^{2,8}$.

\section{Antioxidants}

Antioxidants are molecules which scavenge free radicals and prevent the tissue damage caused by them ${ }^{9}$. The threat of oxidative stress to the organism is so great that an array of antioxidant defenses and repair systems which detoxify oxidants such as superoxide radicals, hydrogen peroxide and lipid hydroperoxides have evolved in the cell. These help to protect it from free radical destruction and to maintain physiological homeostasis ${ }^{4-6}$. These antioxidant defense systems are present in the body to counteract the effects of oxidants. They include non-enzymatic, low molecular weight compounds such as ferritin, ascorbate and alpha tocopherol as well as various enzymatic compounds such as catalase, glucose6-phosphate, glutathione peroxidase and superoxide dismutase $(\mathrm{SOD})^{10}$. The use of antioxidant agents holds significant therapeutic promise for many neurodegenerative processes ${ }^{11-14}$. Plants supply a range of antioxidants such as ascorbate and alpha-tocopherol to humans which help protect the body against free radical damage ${ }^{15}$.

\section{Oxidative stress}

In the context of oxidative stress, free radicals are small molecules or ions that are reactive with small activation energies and have short life time ${ }^{2}$. They are subsets of oxygen or nitrogen species produced during intracellular aerobic metabolism or immune activity. However, there are environmental sources such as pollution, smoke and sunlight ${ }^{2,}, 6$. Oxidative stress is defined as an imbalance between oxidants and antioxidants in favour of the oxidants, potentially leading to tissue damage ${ }^{2,14-17}$. A rise in the intracellular oxidant levels in the body has two potentially important effects: damage to various cell components and activation of specific signaling pathways, both of which can influence numerous cellular processes linked to ageing and the development of age-related diseases ${ }^{4}$. Oxidative stress can damage lipids, proteins, enzymes, carbohydrates and DNA in cells and tissues and can lead to cell death induced by RNA or DNA fragmentation and lipid peroxidation ${ }^{18}$. In humans, several diseases including those connected to the heart, lungs and eyes are associated with these free radicals ${ }^{6}$. The consequences of oxidative stress are the molecular basis in the development of several diseases such as cancer, neurodegenerative disorders, cardiovascular diseases, diabetes and autoimmune disorders ${ }^{9,19-21}$.

\section{Oxidative stress in ocular conditions}

Oxidative stress has been implicated in the pathogenesis of several eye conditions such as corneal disease, cataract, macular degeneration, diabetic retinopathy and retinitis pigmentosa ${ }^{22-27}$.

\section{Corneal and conjunctival diseases}

Lodovici et al 23 measured 8-hydroxy-2'-deoxyguanosine $(8-\mathrm{OHdG})$ levels, a marker of oxidative DNA damage in corneal rabbit-derived cells exposed to UV-B. The levels of $8-\mathrm{OHdG}$ increased significantly $(p<0.01)$ following irradiation. Also, the levels of superoxide dismutase (SOD) activities in the cells 
decreased. These suggest that UVB elicited oxidative DNA damage in the corneal cells. The exposure of the human eye to intense light, metabolic activity and high oxygen tension renders it vulnerable to oxidative damage and the number of ophthalmological disorders implicating reactive oxidative and nitrogen species is rapidly growing ${ }^{28}$. According to Dogru et a ${ }^{29}$ oxidative stress plays a major role in the propagation of cellular injury that results in anterior eye disorders such as dry eyes, conjunctivochalasis, UV light-induced and tobacco smoke-induced ocular surface epithelial damage. Histochemical and biochemical findings in corneas of albino rabbits have suggested that ROS-generating oxidases (xanthine oxidase and D-amino acid oxidase) contribute to corneal damage evoked by UVB rays ${ }^{30}$. A literature review by Ceikova $e a^{31}$ found that increased UVB radiation leads to a profound decrease in corneal antioxidants, resulting in oxidative injury of the cornea. Oxidative stress has been implicated in the pathogenesis and pathophysiology of diseases of the human cornea including pterygium, keratoconus and a host of inflammatory, metabolic, degenerative and iatrogenic conditions ${ }^{28}$.

\section{Cataract}

ROS and oxidative stress are involved in many ocular diseases including cataract ${ }^{26}$. Contemporary hypothesis considers oxidative stress as an important factor in age-related processes in the body including senile cataract ${ }^{32}$. Production of ROS and reduction of endogenous antioxidants both contribute to cataract formation ${ }^{24}$. UV-induced oxidation damage seems to play a major role in a number of specific pathological conditions of intraocular tissues such as cataract and retinal degeneration ${ }^{25}$. The crystalline lens is constantly subjected to oxidative stress from radiation and others sources ${ }^{32}$ and this can damage the crystalline proteins, lipids, polysaccharides and nucleic acids ${ }^{32}$. However, it has several mechanisms to protect its components from oxidative stress and to maintain its redox state. These include enzymatic pathways and high concentration of ascorbate and reduced glutathione ${ }^{33}$. However, with ageing, accumulation of oxidized lens components and decreased efficiency of repair mechanisms can contribute to the development of cataract ${ }^{33}$. Chronic UV-induced ROS formation is believed to be responsible for various degenerative diseases in the eye including cataract formation ${ }^{34}$. According to Berthoud and Beyer ${ }^{33}$, oxidative stress-induced damage to lens gap junctions and consequent altered intercellular communication may contribute to cataract formation.

Lipid peroxidation (LPO) has been proposed as a causative factor of cataract ${ }^{22}$. The authors ${ }^{22}$ found increased concentration of primary molecular LPO products (diene conjugates and lipid peroxides) and end fluorescent LPO products in the lipid moieties of the aqueous humour of patients with senile cataracts compared to those without the condition. Sawada et $a l^{35}$ found a significant increase in superoxide dimutase activity and protein level in nuclear cataracts, suggesting the involvement of oxidative stress. Several other current studies ${ }^{24,36-41}$ have associated oxidative stress with the formation of cataracts.

\section{Glaucoma}

There is an increasing body of evidence suggesting that ROS play a key role in the pathogenesis of primary open angle glaucoma $(\mathrm{POAG})^{42}$. Izzotti et $a l^{42}$ found that oxidative DNA damage was significantly increased in the trabecular meshwork (TM) of glaucomatous patients compared to controls. The authors ${ }^{42}$ reported that oxidative stress occurs, not only in the meshwork but also in retinal cells and appears to be involved in the neuronal death affecting the optic nerve in POAG. According to Saccà and Izzotti43, the perturbation of the oxidants versus antioxidant balance can lead to increased oxidative damage, especially when the first line of antioxidant defense weakens with age. Oxidative stress can cause chronic changes in the aqueous and vitreous humour, which may induce alterations in the trabecular meshwork and the optic nerve head that are seen in glaucoma ${ }^{43}$.

Zanon-Moreno et al $^{44}$ found that glaucomatous eyes had a significant increase in oxidative status and decreased antioxidant activity in the aqueous humor compared with the cataract eyes and concluded that oxidative stress may play a pathogenic role in POAG. Fernandez-Durango et $a l^{45}$ found an increase in the expression and enzymatic activity of nitric oxide synthase (NOS) isoenzymes and nitrotyrosine in the TM of patients with POAG. The increase correlated with visual field defects; hence the authors concluded that 
the increased level of nitrotyrosine may serve as a maker of oxidative stress in the progression of cell death of the TM in patients with $\mathrm{POAG}^{45}$. According to Izzotti et al $^{42}$ the pathogenic role of ROS in POAG has implications for the prevention of the disease as indicated by the growing number of studies using genetic analyses to identify susceptible individuals and of clinical trials testing the efficacy of antioxidant drugs for POAG management.

\section{Macular degeneration (AMD)}

Age-related macular degeneration is a leading cause of blindness in the developed countries ${ }^{46}$. The retinal is highly susceptible to photochemical damage from the continuous exposure to UV, but the relationship between UV light exposure and AMD is unclear, although short wavelength radiation and blue light induce significant oxidative stress to the retinal pigment epithelium ${ }^{46}$. There are several reports that have associated oxidative stress with the cellular damage caused by ROS in the pathogenesis of $\mathrm{AMD}^{47}$. The retina is particularly susceptible to oxidative stress because of its high oxygen consumption, its high proportion of polyunsaturated fatty acids and its exposure to visible light ${ }^{48}$. Klein et al ${ }^{49}$ found that cataract was associated with incidence of early AMD, soft indistinct drusen, increased retinal pigmentation and progression of AMD. As cataract has been associated with oxidative stress, its association with AMD may signal the same etiology. Several risk factors for AMD such as genetics, age, exposure to sunlight and smoking have been reported ${ }^{46}$. In a review by Ambati et al ${ }^{50}$ it was found that photo-oxidative damage to the retina, mediated by ROS were implicated in the development of AMD.

ROS including other free radicals have been implicated in the apoptotic cell death and the development of pathological changes in AMD ${ }^{50-53}$. Janick-Papis et $a l^{54}$ stressed that oxidative stress is a major factor in the pathogenesis of AMD. Retinal pigment epithelium cells are prone to ROS arising from intense oxygen metabolism. Also, the cells can be exposed to ROS as a consequence of accumulation of iron ions in the cells, sunlight exposure and tobacco smoke ${ }^{54}$. The macular pigment formed by two dihydroxycarotenoids, lutein and zeaxanthin is a natural barrier protecting the macula against oxidative stress ${ }^{55}$. However, retinal factors such as intense oxygen metabolism, exposure to ultraviolet radiation, high concentration of polyunsaturated fatty acids and presence of photosensitizers may increase the production of $\operatorname{ROS}^{55}$.

There is experimental evidence in support of oxidative damage to the retinal pigment epithelium and the choriocapillaries that is both light and oxygendependent, however, the precise linkage between oxygen-induced events and the progression of AMD remains unclear ${ }^{56-57}$. It is considered that ROS including free radicals are responsible for apoptotic cell death and the development of pathological changes in $\mathrm{AMD}^{57}$. Research findings have demonstrated that a diet poor in antioxidant micronutrients (vitamin C, E, carotenoids, zinc) and low plasma levels of antioxidants may favor the development of the AMD ${ }^{54}$. San Giovanni and Chew ${ }^{58}$ have reported that omega-3 long-chain polyunsaturated fatty acids exhibit cytoprotective and cytotherapeutic actions providing antiangiogenic and neuroprotective mechanisms within the retina and this may have a protective role against ischemic-, light-, oxygen-, inflammatory-, and agerelated pathology of the vascular and neural retina. It has been reported that micronutrient supplementation enhances antioxidant defense and might prevent or retard AMD or modify the course of the disease ${ }^{55}$.

\section{Retinitis pigmentosa $(R P)$}

Retinitis pigmentosa, a heterogeneous group of inherited retinal disorders characterized by progressive photoreceptor apoptosis, is the leading cause of inherited retinal degeneration-associated blindness worldwide ${ }^{59,60}$. It is a disease in which one of a variety of mutations selectively causes rod photoreceptor cell death, followed by gradual death of cone cells resulting in blindness ${ }^{59}$. According to Komeima et al ${ }^{59}$ although RP is commonly considered to be genetic in origin, oxidative stress plays a role in its pathogenesis. The authors ${ }^{59}$ found that antioxidant-treated mice showed preservation of cone function as shown by a significant increase in scotopic ERG b-wave amplitudes, temporary preservation of scotopic a-wave amplitude, prolonged rod survival and slowed depletion of rhodopsin mRNA. These suggest that oxidative damage contributes to rod and cone cell death. The authors ${ }^{59}$ suggested that protection from oxidative damage may be a broadly applicable treatment strategy in RP. According to Usui et al 61 , following the death of the rod photoreceptors from a variety 
of mutations, the level of tissue oxygen in the outer retina becomes elevated and there was a progressive oxidative damage to cones that ultimately triggers apoptosis. The authors ${ }^{61}$ further reported that NADPH oxidase (Nox) plays a critical role in generation of the oxidative stress that leads to cone cell death in RP and proposed that inhibition of Nox provides a new treatment strategy.

\section{Diabetic retinopathy (DR)}

Diabetes has been implicated in the increased oxidative stress which is thought to play an important role in the pathogenesis of various diabetic complications ${ }^{19-21,62}$, however, the source of the hyperglycemia-induced oxidative stress is not clear ${ }^{19}$. Yue et $a l^{63}$ investigated the correlation between redox status and oxidative stress in the eyes, aorta and kidneys of streptozotocin (STZ)-induced diabetic rats. The primary endogenous antioxidants, glutathione (GSH) and malondialdehyde (MDA) (markers of oxidative stress) in those tissues were measured after streptozotocin (STZ) injection at different times and it was observed that oxidative stress occurred in the eyes and aorta, but not the kidneys of diabetic rats. It was found that ROS generation and lipid peroxidation may play a vital role in the development of diabetic complications in the eyes and aorta and that the administration of vitamin E may prevent ROS-induced lipid peroxidation and thereby limit the development of diabetic complications in the aorta and eyes ${ }^{63}$. Possible sources of oxidative stress and damage to proteins in diabetes include free radicals generated by auto-oxidation reactions of sugars and sugar adducts to proteins ${ }^{64}$. The oxidative stress may be amplified by a continuing cycle of metabolic stress, tissue damage and cell death, leading to increased free radical production and compromised free radical inhibitory and scavenger systems, which further exacerbate the oxidative stress ${ }^{64}$.

\section{Autoimmune uveitis (AIU)}

Autoimmune and inflammatory uveitis are a group of potentially blinding diseases that arise without a known infectious trigger and are often associated with immunological responses to unique retinal proteins ${ }^{65}$. Experimental studies have implicated free radicals in the pathogenesis of this eye condition ${ }^{65-66}$ suggesting that free radicals and oxidative stress play a role in the pathogenesis of the disease. Photoreceptor mitochondrial oxidative stress has been considered to be the initial pathological event in experimental autoimmune uveitis ${ }^{67}$. Determination of alterations in retinal mitochondrial levels in response to oxidative stress during the early phase of experimental autoimmune uveitis showed the presence of mitochondrial-specific oxidative stress-related proteins in the retina along with down regulation of ATP synthase; providing evidence of stress related retinal damage ${ }^{67}$.

\section{Pseudoexofoliation syndrome (PEX)}

Pseudoexfoliation syndrome is a common agerelated fibrillopathy of unknown cause, recognized by chronic deposition of abnormal pseudoexfoliation material on the anterior segment structures of the eye ${ }^{68}$. Oxidative stress has been implicated in the development of this condition. Gartaganis et al ${ }^{69}$ investigated the oxidative status in lens epithelial cells of patients with PEX syndrome and found a decrease in the levels of glutathione (GSH) and glutathione disulphide (GSSG) compared with non-PEX lens epithelial cells, as well as increase in lipid peroxidation product malondialdehyde (MDA) levels. The increased MDA and decreased GSH levels indicate high oxidative stress. Also, GSSG usually increases in cases of high-oxidative stress, although this is not always the case as it may not always accumulate in cells ${ }^{69}$. The authors ${ }^{69}$ concluded that their findings suggest a role for oxidative stress in the pathogenesis and progression of PEX syndrome.

\section{Preventive measures}

Epidemiological and laboratory evidence exists in support of roles for nutritional antioxidants in delaying the onset or prevention of age-related vision disorders. Following a review of nutrition and prevention of cataract, Fernandez and Afshari ${ }^{41}$ indicated that basic research has demonstrated a protective effect of antioxidant on lens tissue and supplementation with vitamin $\mathrm{C}$ and lutein/zeaxanthin has been associated with a decreased risk of cataract formation in multiple observational studies. Mares ${ }^{70}$ reported that supplementation with high-dose antioxidants lowered the progression of lens opacities; also empirical observational evidence suggests that the use of supplements is associated with lower risk for cataract.

Drobek-Slowik et al ${ }^{55}$ have indicated that micro- 
nutrients supplementation enhances antioxidant defense and might retard AMD or modify the course of the disease. According to SanGiovanni and Chew ${ }^{58}$, omega-3 long chain polyunsaturated fatty acids (LCPUFAs) exhibit protective and cytotherapeutic actions contributing to a number of anti-angiogenic and neuroprotective mechanisms within the retina. It may modulate metabolic processes and reduce the effects of environmental exposures that activate the molecules implicated in the pathogenesis of vasoproliferative and neurodegenerative retinal diseases ${ }^{58}$. Evidence of protection against early AMD from regularly eating fish, greater consumption of omega-3 polyunsaturated fatty acids, and low intakes of foods rich in linoleic acid has been provided ${ }^{71}$. According to Fernandez and Afshari ${ }^{41}$, while high doses of multivitamins, antioxidants or lutein and zeaxanthin are unlikely to be of significant benefit to the general public in preventing cataract, these nutrients may help individuals exposed to high oxidative stress such as heavy smokers and those with poor nutrition ${ }^{41}$. Also, Jacques $^{72}$ is of the opinion that although it is not yet possible to conclude that antioxidant nutrients have a role in the prevention of cataract or AMD, it is prudent to consume diets high in vitamins $\mathrm{C}$ and $\mathrm{E}$ and carotenoids, particularly the xanthophylls, to prevent the development of cataract and $\mathrm{AMD}^{72}$.

Phytochemical antioxidant and anti-inflammatory agents may help prevent eye diseases. A high intake of phytochemical lutein and zeaxanthin is safe and has been associated with reducing risks of eye diseases $^{71,73}$. Phytochemical nutrients such as green tea catechins, anthocyanins, resveratrol, and Ginkgo biloba, have been shown to ameliorate ocular oxidative stress, therefore, future clinical trials in this area are required ${ }^{73}$.

In view of these proposed nutritional benefits, it is important that health care professionals advise their patients on diet that may enhance their ocular health or advise them to consult appropriate professionals who may offer appropriate diet regimen.

Important risk factors in the development of AMD include obesity, smoking and inadequate antioxidant status. Cigarette smoke is operationally divided into gas-phase smoke and particulate matter (or tar) ${ }^{74,75}$. Both components are very rich sources of radicals and are highly oxidizing, putting an oxidative stress on the entire organism and on the lungs ${ }^{74,75}$ and has been considered to be the most important environmental risk factor for developing $\mathrm{AMD}^{76}$. In a study to investigate the molecular and cellular effects of cigarette smoke on human retinal pigment epithelium (RPE), Bertram et $a l^{77}$ found evidence of oxidative damage to the RPE caused by cigarette smoke and concluded that cigarette smoke is a potent inducer of oxidative damage and cell death in RPE therefore contributes to AMD pathogenesis. As cigarette smoking is known to be a risk factor for oxidative stress leading to $\mathrm{AMD}^{55,76,77}$ it is essential for eye care practitioners to educate their patients on the adverse effects of smoking and advise them to quit smoking. This will go a long way in reducing the visual impairment associated with smoking.

\section{Conclusion}

Laboratory and epidemiological findings indicate that oxidative stress induced by free radicals has serious implications for both systemic ${ }^{8,} 78-80$ and ocular diseases $28,32,42$. It is important that optometrists and other eye care professionals are aware of the role of oxidants and oxidative stress in the pathogenesis of eye diseases so that they can educate their patients appropriately. Also, they should be conversant with the various sources of dietary and supplementary antioxidants so that they may advise their clients appropriately with regard to dietary intake and supplementation. As smoking has been recognized as an important source of free radicals and oxidative stress ${ }^{55,74-77}$ it is also important that eye care practitioners advise their patients against smoking to reduce the burden of associated diseases.

\section{References}

1. Understanding free radicals and antioxidants. http://www. healthchecksystems com/antioxid.htm. (Accessed on: November 2010).

2. Jensen SJK. Oxidative stress and free radicals. J Mol Struct 2003 666-667 387-392.

3. Herman D. Aging: a theory based on free radical and radiation chemistry. J Gerontol 19562 298-300.

4. Finkel T, Holbrook NJ. Oxidants, oxidative stress and biology of aging. Nature 2000408 239-247.

5. Wickens AP. Aging and free radical theory. Resp Physiol 2001128 397-391.

6. Saleh MA, Clark S, Woodward B, Deolu-Sobogun SA. Antioxidant and free radical scavenging activities of essential 
oils. Ethn Dis 201020 S178-82.

7. Cadenas E, Davies KJA. Mitochondrial free radical generation, oxidative stress, and aging. Free Rad Biol Med 2000 29 222-230.

8. Serra JA, Domínguez RO, Marschoff ER, Guareschi EM, Famulari AL, Boveris A. Systemic oxidative stress associated with the neurological diseases of aging. Neurochem Res 200934 2122-2132.

9. Ratnam DV, Ankola DD, Bhardwaj AV, Sahana DK, Kumar MNVR. Role of antioxidants in prophylaxis and therapy: A pharmaceutical perspective. J Controlled Release 2006113 189-207.

10. Lassen N, Black WJ, Estey T and Vasiliou V. The role of crytallins in the cellular defense mechanisms against oxidative stress. Sem Develop Biol 200819 100-112.

11. Banaclocha MM. Therapeutic potential of N-acetycysteine in age-related neurodegenerative diseases. Med Hypotheses 200156 472-477.

12. Le Prell CG, Hughes LF, Miller JM. Free radical scavenging vitamins $\mathrm{A}, \mathrm{C}$ and $\mathrm{E}$ and magnesium reduce noise trauma. Free Rad Biol Med 200142 1454-1463.

13. Calabrese V, Lodi R, Tonon C, D’Agata V, Sapenza M, Scapagnini G, Mangiameli A, Pennisi H, Stella AM, Butterfield DA. Oxidative stress, mitochondrial dysfunction and cellular stress response in Friedreich ataxia. J Neurol Sci 2005233 145-162.

14. Mayo JC, Sainz RM, Tan DX, Antolin I, Rodriquez C, Reiter RJ. Melatonin and Parkinson's diseases. Endocrine 2005 27 169-178.

15. Halliwell B. The wandering of a free radical. Free Rad Biol Med 200946 531-542.

16. Beal MF. Mitochondria take center stage in aging and neurodegeneration. Ann Neurol 200558 495-505.

17. Casetta I, Govoni V, Granieri E. Oxidative stress, antioxidants and neurodegenerative diseases. Curr Pharm Design 200511 2033-2052.

18. Beckman KB, Ames BN. The free radical theory of aging matures. Physiol Rev 199878 547-581.

19. Feldmen EL. Oxidative stress and diabetic retinopathy: a new understanding of an old problem. J Clin Invest 2003 111 431-433.

20. Brownlee M. The pathophysiology of diabetic implications: a unifying mechanism. Diabetes 200554 1615-1625.

21. Kowluru RA, Kanwar M. Oxidative stress and the development of diabetic retinopathy: Contributory role of matrix metalloproteinase-2. Free Rad Biol Med 200946 16771685.

22. Babizhayev MA. Failure to withstand oxidative stress induced by phospholipid peroxides as a possible cause of lens opacities in systemic diseases and aging. Biochem Biophys Acta 19961315 87-99.

23. Lodovici M, Raimondi L, Guqlielmi F, Gemignani S, Dolara P. Protection against ultraviolet B-induced oxidative DNA damage in rabbit corneal-derived cells (SIRC) by 4-counmaric acid. Toxicol 2003184 141-7.

24. Ho M-C, Peng Y-J, Chen S-J, Chiou S-H. Senile cataract and oxidative stress. J Clin Gerontol and Geriat 20101 $17-21$
25. Lodovici M, Caldini S, Morbidelli L, Ziche M and Dolara P. Protective effect of 4-coumaric acid from UVB ray damage in the rabbit eye. Toxicol 2009255 1-5.

26. Ohira A, Ueda T, Ohishi K, Hiramitsu T, Akeo K, Obara Y. Oxidative stress in ocular disease. Nippon Ganka Gakkai Zasshi 2008112 22-9.

27. Vinson JA. Oxidative stress in cataract. Pathophysiol 2006 13 151-162.

28. Shoham A, Hadziahmetovic M, Dunaief JL, Mydlarski MB, Schipper HM. Oxidative stress in the disease of the cornea. Free Rad Biol Med 200845 1047-1055.

29. Dogru M, Wakamatsu T, Kojima T, Matsumoto Y, Kawatika $\mathrm{T}$, Schnider CCO, Tsubota K. The role of oxidative stress and inflammation in dry eye disease. Cornea 200928 S70S74.

30. Cejková J, Stipek S, Crkovska J, Ardan T, Midelfart A. Reactive oxygen species (ROS)-generating oxidases in the normal rabbit cornea and their involvement in the corneal damage evoked by UVB rays. Histol Histopathol 200116 523-533.

31. Cejková J, Stipek S, Crkovska J, Ardan T, Platenik JM Ceika C, Midelfart A. UV rays, the pro-oxidant / anti-oxidant imbalance in the cornea and oxidative eye damage. Physiol Res 200453 1-10.

32. Zoric L. Parameters of oxidative stress in the lens. Aqueous humor and blood in patients with diabetes and senile cataracts. Srp Arh Celok Lek 2003131 137-42.

33. Berthoud VM, Beyer EC. Oxidative stress, lens gap junctions, and cataract. Antioxid Redox Signal 200911 339-353.

34. Javitt JC Taylor HR. Cataract and latitude. Doc Ophthalmol 199488 307-325.

35. Sawada H, Fukuchi T, Abe H. Oxidative stress in aqueous humor of patients with senile macular degeneration. Curr Eye Res 200934 36-41.

36. Gul A, Rahman MA, Hasnain SN, Salim A, Simiee SU. Could oxidative stress associate with age products in cataractogenesis? Curr Eye Res 200833 669-675.

37. Ottonello S, Foroni C, Carta A, Petrucco S, Maraini G. Oxidative stress and age-related cataract. Ophthalmologica 2000214 78-85.

38. Yildirim Z, Yildrim F, Ucgun NI, Kilic N. The evaluation of oxidative stress parameters in non-diabetic and diabetic senile cataract patients. Biol Trace Elem Res 2009128 135143.

39. Rumyantseve YV, Fursova AZH, Fedoseeva LA, Kolosova NG. Changes in physiochemical parameters and alpha-crystallin expression in the lens during cataract development in OXYS rats. Biochem (Mosc) 200873 1176-1182.

40. Li L, Duker JD, Yoshida Y, Niki E, Rasmussen H, Russell RM, Yeum KJ. Oxidative stress and antioxidant status in older adults with early cataract. Eye 200923 1464-1468.

41. Fernandez MM, Afshari NA. Nutrition and prevention of cataracts. Curr Opin Ophthalmol 200819 66-70.

42. Izzotti A, Bagnis A, Saccà SC. The role of oxidative stress in glaucoma. Mutat Res 2006612 105-114.

43. Saccà SC, Izzotti A. Oxidative stress and glaucoma: injury in the anterior segment of the eye. Prog Brain Res 2008173 385-407. 
44. Zanon-Moreno V, Marco-Ventura P, Lleo-Perez A, PonsVazquez S, Garcia-Medina JJ, Vinuesa-Silva I, MorenoNadal MA, Pinazo-Duran MD. Oxidative stress in primary open angle glaucoma. J Glau 200817 263-268.

45. Fernández-Durango R, Fernández-Martínez A, García-Feijoo J, Castillo A, de la Casa JM, García-Bueno B, PérezNievas BG, Fernández-Cruz A, Leza JC. Expression of nitrotyrosine and oxidative consequences in the trabecular meshwork of patients with primary open-angle glaucoma. Invest Ophthalmol Vis Sci 200849 2506-2511.

46. Chalam KV, Khetpal V, Rusovici R, Balaiy S. A review: role of ultraviolet radiation in age-related macular degeneration. Eye Contact Lens 201137 225-232.

47 Ohia SE, Opere CA, Leday AM. Pharmacological consequences of oxidative stress in ocular tissues. Mutat Res 2005579 22-36.

48. Beatty S, Koh H, Henson D, Boulton M. The role of oxidative stress in the pathogenesis of age-related macular degeneration. Surv Ophthalmol 200045 115-134.

49. Klein R, Klein BE, Wong TY, Tomany SC, Cruickshanks KJ. The association of cataract and cataract surgery with long term incidence of age-related maculopathy. The Beaver Dam Study. Arch Ophthalmol 2002120 1551-1558.

50. Ambati J, Ambati B, Yoo SH, Lanchuley S, Adamis AP. Age-related macular degeneration: Etiology, pathogenesis and therapeutic strategies. Surv Ophthalmol $200348257-$ 293.

51. Gottsch JD, Bynoe LA, Harlan JB Rencs EV, Green WR. Light-induced deposits in the Bruch's membrane of proptoporphyric mice. Arch Ophthalmol 1993111 126-129.

52. Nowak M, Gnitecki W, Jurowski P. The role of retinal oxygen in the origin of macular degeneration (AMD). Klin Oczna 2005107 715-718.

53. Wu J, Seregard S, Algvere PV. Photochemical damage of the Retina. Surv Ophthalmol 200651 461-481.

54. Janik-Papis K, Ulińska M, Krzyzabowska A, Stockzyńska E, Borucka A, Woźniak K, Małgorzata Z, Szaflik JP, Blasiak J. Role of oxidative mechanisms in the pathogenesis of age-related macular degeneration. Klin Oczna 2009111 168-173.

55. Drobek-Slowik M, Karczewicz D, Safranow K. The potential role of oxidative stress in the pathogenesis of the agerelated macular degeneration (AMD). Postepy Hig Med Dosw 200761 28-37.

56. Winkler BS, Boulton ME, Gottsch JD, Sternberg P. Oxidative damage and age-related macular degeneration. Mol Vis $1999532-42$.

57. Roehlecke C, Schaller A, Knels L, Funk RH. The influence of sublethal blue light exposure on human RPE cells. Mol Vis 200915 1929-1938.

58. SanGiovanni JP, Chew EY. The role of omega-3 long chain polyunsaturated fatty acids in health and disease of the retina. Prog Retina Res 200524 87-138.

59. Komeima K, Rogers BS, Campochiaro PA. Antioxidants slow photoreceptor cell death in mouse models of retinitis pigmentosa. J Cell Physiol 2007213 809-815.
60. Shintani K, Shechtman DL, Gurwood AS. Review and Update: Current treatment trends for patients with retinitis pigmentosa. Optom 200980 384-401.

61. Usui S, Ovesson BC, Lee SY, Jo YJ, Yoshida T, Miki A, Miki K, Iwase T, Lu L, Compochiaro PA. NADPH oxidase plays a central role in cone cell death in retinitis pigmentosa. J Neurochem 2009110 1028-37.

62. Kowluru RA, Abbas SN. Diabetes-induced mitochondrial dysfunction in the retina. Invest Ophthalmol Vis Sci 2003 44 5327-5334.

63. Yue KKM, Chung WS, Leung AWN, Cheung CHK. Redox changes precede the occurrence of oxidative stress in eyes and aorta, but not kidneys of diabetic rats. Life Sci 200373 2557-2570.

64. Baynes JW. Role of oxidative stress in development of complications in diabetes. Diabetes 199140 405-412.

65. Caspi RR. A look at autoimmunity and inflammation of the eye. J Clin Invest 2010120 3073-3083.

66. Zamir E, Zhang Z, Samuni A, Kogan M, Pe'er J. Nitroxide stable radical suppresses autoimmune uveitis in rats. Free Rad Biol Med 199927 7-15.

67. Sarawathy S, Rao, NA. Mitochondrial proteomics in experimental autoimmune uveitis oxidative stress. Invest Ophthalmol Vis Sci $2009505559-5566$.

68. Schumacher S, Schlotzer-Schrehardt U, Martus P, Lang W, Nuamann GOH. Pseudoexfolic syndrome and aneurysm of the abdominal aorta. Lancet 2001357 359-360.

69. Gartaganis SP, Patsoukis NE, Nikolopoulos DK, Georgiou CD. Evidence for oxidative stress in lens epithelial cells in pseudoexfoliation syndrome. Eye 200721 1406-1411.

70. Mares JA. High-dose antioxidant supplementation and cataract risk. Nutr Rev 200462 28-32.

71. Tan JS, Wang JJ, Flood V, Mitchell P. Dietary fatty acids and the 10-year incidence of age-related macular degeneration: the Blues Mountain Eye Study. Arch Ophthalmol 2009127 656-665.

72. Jacques PF. The potential preventive effects of vitamins for cataract and age-related macular degeneration. Int J Vitam Nutr Res 199969 198-205.

73. Rhone M, Basu A. Phytochemicals and age-related eye diseases. Nutr Rev 200866 465-472.

74. Penn A, Synder CA. Inhalation of sidestream cigarette smoke accelerates development of arteriosclerotic plagues. Circulation 199388 1820-1825.

75. Pryor WA. Cigarette smoke radicals and the role of free radicals in chemical carcinogenicity. Environ Health Perspect 1997105 875-882.

76. Cano M, Thimmalappula R, Fujihara M, Nagai N, Sporn M, Wang AL, Neufeld AH, Biswal S, Handa JT. Cigarette smoking, oxidative stress, the anti-oxidant response through Nrf2 signaling, and age-related macular degeneration. Vis Res 201050 652-664.

77. Bertram KM, Baglole CJ, Phipps RP, Libby RT. Molecular regulation of cigarette smoke induced oxidative stress in human retinal pigment epithelial cells. Implications for agerelated macular degeneration. Am J Cell Physiol 2009297 1200-1210. 
78. Valko M, Rhodes CJ. Moncol J, Izakovich M Mazur M. Free radicals, metals and oxidants in oxidative stress-induced cancer. Chem Biol Interact 2006160 1-40.

79. Fearon IM, Faux SP. Oxidative stress and cardiovascular disease. Novel tools give (free) radical insight. J Mol Cardiol 200947 372-381.

80. Cherubini A, Ruggierro C, Polidori MC, Mecocci P. Potential markers of oxidative stress in stroke. Free Rad Biol Med 200539 841-852. 